\title{
SENTIDOS DA/PARA A FORMAÇÃO DE PROFESSORAS COORDENADORAS: lições da experiência
}

\author{
Renata Cristina Oliveira Barrichelo Cunha \\ Keila Santos Pinto
}

\section{Resumo}

$\mathrm{O}$ artigo discorre sobre o processo formativo de professoras coordenadoras ao longo de um curso promovido pela Secretaria Municipal da Educação de um município paulista. A pesquisa teve como objetivos compreender os sentidos atribuídos a essa formação e os modos de estar na escola como professoras coordenadoras. Os dados de análise são compostos de cartas endereçadas às formadoras apontando os sentimentos, expectativas e necessidades formativas. As análises, orientadas pelo paradigma indiciário, evidenciaram que a formação foi compreendida como um momento de interrupção da rotina e possibilidade de deslocamento do olhar e, consequentemente, atribuição de sentido para o trabalho. Estar entre os colegas compartilhando ideias e sentimentos contribuiu com o sentimento de pertencimento no grupo e valorização da função.

Palavras-chave: formação continuada; formação de formadores; professoras coordenadoras; cotidiano escolar.

\section{MEANINGS OF/FOR THE COORDINATING TEACHERS'} TRAINING:

lessons from an experience

\begin{abstract}
The article expatiates on the training process of coordinating teachers throughout a course promoted by the Municipal Department of Education of a city in the state of São Paulo. The research aimed to comprehend the meanings given to this training process and the ways of being at school as coordinating teachers. The analysis data are composed of letters addressed to the instructors pointing out feelings, expectations and formative needs. The analysis, guided by the evidential paradigm, indicated that the training was understood as a moment of routine's interruption and a possibility of changing the perspective and, consequently, assigning meaning to the work. Being among colleagues sharing ideas and feelings contributed to the sense of belonging to the group and appreciation of the function.
\end{abstract}

Keywords: continuous professional development; teacher training; coordinating teacher; school routine.

\section{SENTIDOS DE LA/PARA LA FORMACIÓN DE PROFESORAS COORDINADORAS: lecciones de una experiencia}

Resumen

El artículo discurre sobre el proceso formativo de profesoras coordinadoras a lo largo de un curso ofrecido por la Secretaría Municipal de la Educación de un municipio paulista. La investigación tuve como objetivos comprender los sentidos atribuidos a esa formación y la posición de estar en la escuela como profesoras 
DOI: $10.12957 /$ teias. $\%$ Y.50940

coordinadoras. Son compuestos los datos de la encuesta de cartas direccionadas a las formadoras señalando los sentimientos, expectativas y necesidades formativas. Los análisis, orientados por el paradigma indiciario, evidenciaron que la formación fue comprendida como un momento de interrupción de la rutina y posibilidad de cambio de la mirada y, consecuentemente, fue atribuido sentido para el trabajo. Estar entre los mismos profesionales compartiendo ideas y sentimientos contribuyeron con el sentimiento de pertenencia al grupo y valoración de la función.

Palabras clave: formación continua; formación de formadores; profesoras coordinadoras; cotidiano escolar.

\section{INTRODUÇÃO}

Partindo do pressuposto que a formação continuada não está dissociada do próprio trabalho docente, este artigo discorre sobre o processo formativo de professoras coordenadoras ${ }^{1}$ da rede municipal de Rio Claro/SP e problematiza a formação e atuação dessas profissionais face à complexidade do cotidiano escolar. Concebemos as professoras coordenadoras como as interlocutoras privilegiadas entre os professores em suas reflexões sobre a prática e responsáveis por promover a formação continuada no contexto das escolas.

A documentação da experiência de formação oferecida pela Secretaria Municipal da Educação (SME) ao longo de um curso de 30h ocorrido entre os meses de maio a julho de 2018, refletida e tomada como objeto de investigação pelas organizadoras do curso e autoras deste trabalho, foi orientada pelos objetivos de compreender os sentidos atribuídos à formação e os modos de estar na escola como professoras coordenadoras.

Ao final do curso, que se propôs a discutir as funções das professoras coordenadoras como formadoras de professores e articuladoras do trabalho coletivo, foi solicitado que as participantes elaborassem cartas endereçadas às organizadoras narrando a experiência formativa dos encontros.

Assumindo a experiência como "[...] o que nos passa, o que nos acontece, o que nos toca" (LARROSA, 2002, p. 21), a proposta era ouvi-las para compreender como foram afetadas pela formação de modo que suas necessidades e expectativas fossem consideradas na continuidade das ações formativas da SME.

Concordamos com Gatti (2003) quando afirma que os professores (e professores coordenadores) são sujeitos sociais que partilham uma cultura - conhecimentos, valores, atitudes construídas a partir de múltiplas interações. Nesse sentido, os conhecimentos postos em circulação nos cursos de formação adquirem sentido ou não em função de aspectos cognitivos e afetivos, mas também de aspectos culturais relacionados à vida e às condições sociais daquele grupo.

A escuta do que os profissionais têm a dizer sobre as experiências da formação supõe considerar sua cultura e suas condições sociais e, sobretudo, respeitar seus saberes profissionais.

\section{A FORMAÇÃO DO PROFESSOR COORDENADOR COMO FORMADOR}

A formação dos professores coordenadores é objeto de discussão de vários autores (PLACCO, ALMEIDA, SOUZA, 2011; PLACCO, SOUZA, ALMEIDA, 2012; CUNHA, OMETTO, PRADO, 2013; MIZIARA, RIBEIRO, BEZERRA, 2014) e, de modo geral, todos

\footnotetext{
1 A opção pelo gênero feminino na apresentação do texto e no título justifica-se pelo fato de que o grupo envolvido com a pesquisa era majoritariamente feminino.
} 
DOI: $10.12957 /$ teias. $\%$ Y.50940

concordam que, no conjunto de suas atribuições, as funções formadora, articuladora e transformadora são as mais importantes.

Para Placco, Souza e Almeida (2012, p. 758):

[...] o coordenador pedagógico [ou professor coordenador] tem papel fundamental na gestão dos processos escolares, sobretudo na formação de professores, e que o investimento na formação continuada dos docentes é um dos caminhos para a melhoria da qualidade da educação básica no país - o que exige também investimento na formação inicial e continuada do próprio coordenador.

Admitir o professor coordenador como formador dos professores implica reconhecê-lo como "[...] um dos educadores que participa do projeto pedagógico da escola e está engajado em movimentos de reflexão, internos e externos às instituições que atua" (CLEMENTI, 2001, p. 65) e como educador em formação. Implica, também, valorizar a escola como lugar onde os professores e professores coordenadores aprendem a sua profissão, ou seja, como espaço de aprendizagem profissional (CANÁRIO, 2001).

Em que pesem as críticas às lacunas da formação inicial (PLACCO, SOUZA, ALMEIDA, 2012), a formação continuada dos professores coordenadores desempenha papel importante por criar oportunidades de reflexões sobre as experiências e práticas profissionais concretas e contextualizadas.

Como já destacado por Cunha (2014), há necessidade de que as redes de ensino instituam condições de formação continuada e de trabalho orientadas por uma dinâmica de interlocução entre pares, entre práticas e teorias, entre professores coordenadores e professores universitários, na expectativa de que essas experiências formativas contribuam com o desenvolvimento profissional do grupo e dos projetos educativos da própria rede de ensino.

Essa proposição é coerente com a perspectiva defendida por Nóvoa (2009) de que a formação de professores (e dos demais profissionais da educação) precisa ser construída dentro da profissão. Isso significa que a escola deve ser considerada como objeto de análise dos professores coordenadores e que a partilha de práticas pode transformar a experiência individual e coletiva em conhecimento profissional. Como bem observado pelo autor, a docência e o cotidiano escolar são marcados por dilemas e por conflitos para os quais os professores (e professores coordenadores) não têm respostas prontas.

As formações dirigidas às professoras coordenadoras da SME de Rio Claro/SP vêm se orientando por esse conjunto de pressupostos na expectativa de contribuir com o desenvolvimento profissional desse grupo e, em decorrência, contribuir com a construção de escolas reflexivas e uma "rede de ensino reflexiva".

Segundo Alarcão (2001, p. 13) uma escola reflexiva é uma

[...] organização que continuadamente se pensa a si própria, na sua missão social e na sua estrutura, e se confronta com o desenrolar da sua atividade num processo simultaneamente avaliativo e formativo.

O esforço por construir uma "rede de ensino reflexiva", nessa perspectiva, implica assumir que as escolas estão em processo de desenvolvimento e aprendizagem permanentes, precisam ser 
apoiadas por um referencial teórico e prática reflexiva crítica, bem como construir sua proposta pedagógica a partir do diálogo entre seus membros e orientadas por objetivos comuns ${ }^{2}$.

Essa é uma tarefa contínua para a SME de Rio Claro/SP, que conta com 60 escolas e doze Programas Educação Integral, com aproximadamente 20 mil alunos matriculados na educação infantil - etapa I (0-3 anos) e etapa II (4-5 anos), ensino fundamental I, ensino fundamental II, educação de jovens e adultos I e II e educação especial.

Todas as escolas possuem uma equipe gestora formada pelo diretor de escola, vice-diretor e professor coordenador e, dependendo da complexidade das escolas e número de alunos, a equipe gestora pode contar com mais de um vice-diretor ou professor coordenador.

Em 2020 a rede conta com 64 professores efetivos que, afastados de seus cargos, exercem a função de professores coordenadores. O professor coordenador é designado para a função de confiança do magistério por meio de eleição, conforme as especificidades apresentadas no Estatuto do Magistério Público Municipal (RIO CLARO, 2007) e no Decreto no 11.578/2019 (RIO CLARO, 2019).

O processo de eleição e designação de professor coordenador é promovido quando há vacância da função nas escolas do município e compreende algumas etapas, após a publicação do edital: a) o credenciamento junto à SME com inscrição do Plano de Trabalho, que deve contemplar: introdução, diagnóstico do processo ensino-aprendizagem da escola, objetivos do trabalho pedagógico a ser realizado, proposta de ações a serem desenvolvidas, formas de registro e acompanhamento do trabalho pedagógico, avaliação do trabalho e referências; b) avaliação do Plano de Trabalho por comissão instituída pela SME, composta pelo diretor de departamento pedagógico, supervisor de ensino da escola, coordenador do Centro de Aperfeiçoamento Pedagógico, diretor e vice-diretor da escola c) apresentação oral do Plano de Trabalho pelo candidato à comissão da SME; d) apresentação oral do Plano de Trabalho pelo candidato ao corpo docente e equipe gestora da unidade educacional; nessa última fase é realizada a votação e o candidato precisa ser aprovado com 50\% (cinquenta por cento) mais 1 (um) do total de votos. A cada dois anos o professor coordenador eleito passa pelo processo de avaliação do seu trabalho pelo corpo docente, direção da escola e SME.

Exercendo a função de confiança, o professor coordenador tem como atribuições gerais coordenar, acompanhar, avaliar e propor alternativas de solução do processo pedagógico no âmbito da unidade educacional. As atribuições específicas são coordenar as atividades de planejamento, organização, coordenação, controle e avaliação da ação docente; assistir o diretor de escola na coordenação e elaboração do planejamento didático-pedagógico da escola, de modo a garantir a sua unidade e a efetiva participação do corpo docente e dos demais servidores da unidade; coletar informações e sistematizar dados específicos que subsidiem as tarefas do acompanhamento, avaliação, controle e integração do currículo; promover reuniões periódicas com professores para avaliação do trabalho didático e levantamento de situações que reclamem mudanças de métodos e processos, bem como aprimoramento das funções docentes; coordenar, orientar, acompanhar e avaliar as atividades relacionadas ao cumprimento das horas de trabalho pedagógicos dos docentes no local de trabalho; colaborar no processo de identificação das características básicas da

\footnotetext{
2 O conceito de escola reflexiva e a expressão "rede de ensino reflexiva" devem ser compreendidos no contexto de elaboração teórica de seus autores e não na versão adotada pelas políticas neoliberais que relacionam a reflexão à solução instrumental e imediatista dos problemas da sala de aula, sem considerar os contextos sociopolítico e cultural.
} 
comunidade e clientela escolar; colaborar no processo de integração escola-família-comunidade (RIO CLARO, 2007).

Há alguns anos a SME vem priorizando a formação continuada dos profissionais da educação e tem visto o professor coordenador, como já destacado, como articulador nos processos pedagógicos e formador dos professores e demais educadores no âmbito das escolas.

Um espaço de formação importante na rede municipal da educação é previsto pelo Decreto $n^{\circ}$. 8604/2009 (RIO CLARO, 2009). As Horas de Trabalho Pedagógico (HTP) correspondem às horas destinadas ao aperfeiçoamento do trabalho docente e os encontros dos professores são mediados pelo professor coordenador, que é o responsável pelo planejamento, organização e acompanhamento do trabalho do grupo. De acordo com a Resolução SME 003/2019 (RIO CLARO, 2019), as HTP constituem a jornada de trabalho docente, representam $1 / 3$ do total e são divididas em: I. 20\% de Hora de Trabalho Pedagógico Coletivo - HTPC; II. 50\% de Hora de Trabalho Pedagógico Individual - HTPI; III. 30\% de Hora de Trabalho Pedagógico Livre - HTPL.

Para contribuir com a formação continuada de professores, além das HTP, são oferecidos aos docentes e demais educadores cursos, palestras, oficinas, dentre outros, assim como incentivos à participação em congressos, simpósios e demais eventos educacionais. Acreditando na responsabilidade e comprometimento do professor coordenador com a formação dos profissionais da educação, há anos são realizados na SME grupos de estudos, reuniões e cursos que auxiliam o trabalho desse profissional nas escolas. Esses encontros são organizados pelo Centro de Aperfeiçoamento Pedagógico (CAP) e alguns deles em parceira com professores pesquisadores de universidades, faculdades e institutos federais.

\section{ENCAMINHAMENTOS METODOLÓGICOS}

O curso que é objeto de reflexão e análise deste artigo fez parte do conjunto de ações formativas dirigidas às professoras coordenadoras da rede. Foi organizado em oito encontros (30h), durante os meses de maio a julho de 2018, sendo oferecido nas dependências da SME durante a jornada de trabalho das professoras coordenadoras.

O objetivo principal do curso foi problematizar as funções das professoras coordenadoras como formadoras de professores e articuladoras do trabalho coletivo frente às múltiplas demandas do cotidiano escolar e o desafio de contribuir com uma cultura de colaboração e partilha de conhecimentos atenta às necessidades da infância, à dimensão estética da formação e às práticas inclusivas.

Participaram da formação 49 professoras coordenadoras, três diretores de escolas e cinco vice-diretores ${ }^{3}$ da rede. Cada encontro contou com a participação de convidados (palestrantes) de outras redes de ensino que compartilharam seus saberes da formação e da profissão e suas experiências mais significativas.

Todos os convidados exerceram ou exerciam a função de professoras coordenadoras e se propuseram a discutir a temática do encontro específico - o papel do professor coordenador; o trabalho coletivo e a formação dos professores; o lúdico, o jogo e a brincadeira; o ensino de inglês

\footnotetext{
${ }^{3}$ Nas escolas que estavam em processo de eleição e designação do professor coordenador, as atribuições da função do professor coordenador eram realizadas por outro membro da equipe gestora e seus representantes também participaram dessa formação. Houve também a participação dos vice-diretores de projetos, atualmente nomeados de Programa Educação Integral, vinculados às escolas municipais.
} 
na escola pública; a educação estética na escola; o atendimento educacional especializado e as práticas inclusivas - considerando o professor coordenador como um interlocutor privilegiado dos professores na reflexão crítica de suas práticas pedagógicas.

Dado que os espaços de formação fomentam a pesquisa na medida em que permitem produzir compreensões imersas na multiplicidade de saberes e fazeres que interrogam práticas e teorias, definimos os objetivos de compreender os sentidos atribuídos à formação e os modos de estar na escola como professoras coordenadoras.

Solicitamos às participantes, no encerramento do curso, que escrevessem cartas apontando os sentimentos, expectativas, necessidades, sugestões, críticas, reflexões, ou seja, movimentos disparados nos encontros, com a intenção de levantar elementos que respondessem nossos objetivos.

Compreendemos que o espaço de formação se traduz como um encontro polifônico e que ao narrar e sistematizar as experiências formativas por escrito, a professora coordenadora não só compartilha suas concepções, saberes e práticas, mas tem oportunidade, numa perspectiva dialógica, de analisar como a dimensão do encontro com o outro produz nela questionamentos e respostas.

Quem eu sou? O que produz em mim a presença do outro? Uma resposta possível: compreender que temos a identidade que os outros dão. Mas há no interior mesmo desta identidade socialmente construída, uma intimidade que articula respostas, imposições, significações, incertezas (GERALDI, 2010, p. 4546).

Nossa pretensão foi compreender essas narrativas atribuindo-lhes significados da experiência vivida e expandir os olhares para a formação das professoras coordenadoras e, consequentemente, de professores, de forma a intervir na realidade que, segundo Freire (2011), é uma tarefa complexa e geradora de novos saberes, uma ação que vai além da simples adaptação e exige de nós uma posição não ingênua e muito menos neutra.

Para elucidar o trabalho formativo desenvolvido com as professoras coordenadoras na busca por ampliar a compreensão desses modos de estar na escola, as cartas redigidas por elas tornaram-se saberes compartilhados "[...] numa perspectiva discursiva, dialógica e polifônica, compreendendo que o campo nos confronta com os eventos de linguagem marcados pela interlocução" (JOBIM, SOUZA, 2003, p. 34).

A análise das cartas foi realizada por meio do paradigma indiciário de Ginzburg (1989), buscando um olhar diferenciado para pormenores que poderiam parecer negligenciáveis. De acordo com o autor, é preciso ficarmos atentos às pistas para que possamos compreender as marcas singulares e únicas que apresentam a multiplicidade dos modos de ser e fazer.

Assim, com a intenção de buscar dados que revelassem a singularidade da experiência dos participantes (GINZBURG, 1989), buscamos indícios que respondessem aos objetivos anunciados considerando, ainda, a proposição de Larrosa (2006) sobre a potência da linguagem enquanto formação e interpretação do mundo da vida.

Vimos no recurso das cartas a potencialidade de exercitar a escrita reflexiva das professoras coordenadoras e a leitura/olhar investigadores das formadoras/pesquisadoras. Em comum, dois movimentos de produção de sentidos que buscam compreender a experiência de formação a partir do lugar de enunciadores, estabelecendo uma relação de construção de interpretações e compreensões sobre o que lhes acontecem, pois, segundo Collares, Moysés e Geraldi (1999), esse percurso compõe a essência das narrativas de experiências. 


\section{DA ESCRITA À LEITURA DAS CARTAS}

A leitura das cartas confirmou as palavras de Soligo (2007, p. 340): as cartas são generosas, revelam a singularidade das pessoas, "[...] narram a história das expectativas, das inquietações, das intimidades, registram o movimento dos relacionamentos". E podem ser pedagógicas quando organizam os elementos da experiência e oferecem oportunidades para a reflexão crítica individual e coletiva.

Dentre as cartas lidas e diante de nossos objetivos fomos nos deparando com indícios (signos) que revelavam determinados sentidos atribuídos à formação compartilhada no curso e alguns modos de estar na escola como professoras coordenadoras.

A análise desses indícios nos permitiu compreender que os encontros de formação se constituíram como oportunidades para as professoras coordenadoras "pararem" e "refletirem", interrompendo a rotina; ampliação das possibilidades de atribuir sentido ao trabalho; e, ainda, reforço do sentimento de pertencimento no grupo, ao estar aprendendo e colaborando com os pares.

Em relação ao tempo de pausa que interrompe a rotina, é importante destacarmos que vivenciamos enquanto sociedade o tempo acelerado e a escola, como instituição coletiva, não escapa dessa ação do tempo, já que é cooptada pelo tempo Khrónos, o tempo do capital, do mercado. Cada vez mais é preciso justificar a produtividade com que se experimenta o tempo, um tempo linear que organiza o trabalho pedagógico (KOHAN, 2017).

A questão é que o khrónos, essa sequência sucessiva, irreversível e consecutiva de movimentos que a escola empenha-se em sacralizar não só não é o tempo da ciência, mas também não é o tempo da vida e muito menos é o tempo da infância (KOHAN, 2017, p.13).

Pinto (2016) destaca, inclusive, que diante do tempo acelerado e das ações automatizadas urge a necessidade de refletirmos sobre a postura do educador e a concepção de infância. Sendo dessa forma, possível potencializar as interações que permeiam o cotidiano educacional marcado por realidades, muitas vezes duras, que entrelaçam histórias de desigualdades e injustiças, imersas em situações sociais que podem paralisar o educador, contribuindo para o processo de desvalorização profissional e descrença na educação.

Para as professoras coordenadoras, os encontros de formação propiciaram reflexão crítica e distanciamento da rotina escolar, ao mesmo tempo que possibilitaram apropriarem-se de contribuições que enriqueceram sua prática pedagógica. As cartas deixaram pistas importantes sobre a valorização dos participantes por estarem em outro ambiente que não fosse a escola, para que pudessem olhar para seu contexto escolar.

Os enunciados a seguir evidenciam essa necessidade:

[...] "Parar" para estudar e refletir foi essencial. Adorei os dias da formação, pois pude vir com a cabeça mais tranquila e absorver mais, sem ficar pensando sobre "o que tenho que fazer ou preciso resolver algo". Aurora.

[...] Este momento de se distanciar da escola e poder refletir com meus pares sobre o papel do professor coordenador foi muito importante, visto que isso não é possivel na escola diante da demanda que temos em nossa rotina. Letícia. 
"Parar", "refletir", "se distanciar da escola" em contraposição às exigências de "tenho que fazer", "preciso resolver" e "demanda" sugerem que a formação é um espaço privilegiado de interrupção na rotina para que a experiência, como destacado por Larrosa (2002), seja apropriada pelo sujeito.

Segundo o autor, a experiência tem sido cada vez mais rara, entre outras razões, pela falta de tempo. Tudo tem que ser respondido prontamente, todos têm pressa, busca-se a novidade, há um sentimento de urgência, não há tempo para pensar. Argumenta, no entanto, que a experiência,

$[\ldots]$ a possibilidade de que algo nos aconteça ou nos toque, requer um gesto de interrupção, um gesto que é quase impossível nos tempos que correm: requer parar para pensar, parar para olhar, parar para escutar, pensar mais devagar, olhar mais devagar, e escutar mais devagar; parar para sentir, sentir mais devagar, demorar-se nos detalhes, suspender a opinião, suspender o juízo, suspender a vontade, suspender o automatismo da ação, cultivar a atenção e a delicadeza, abrir os olhos e os ouvidos, falar sobre o que nos acontece, aprender a lentidão, escutar aos outros, cultivar a arte do encontro, calar muito, ter paciência e dar-se tempo e espaço (LARROSA, 2002, p. 24).

Só é possível atribuir sentido a algo quando somos tocados e afetados, quando esse algo faz parte de nós e não está desconectado da realidade (LARROSA, 2002, 2006), quando é possibilitada a interlocução e alteridade na dimensão do encontro com o outro (BAKHTIN, 2011), quando a profissão docente não se reduz a um conjunto de competências e capacidades técnicas, mas amplia-se como oportunidade de compartilhar saberes e produzir conhecimento.

Segundo Kolb-Bernardes (2010), trabalhar com a formação humana não é um empreendimento solitário, mas um investimento que envolve o outro, através de um olhar sensível.

A participação no curso, como evidenciado no enunciado abaixo, possibilitou a uma das professoras coordenadoras a reflexão crítica sobre o sentido do seu trabalho, a finalidade da educação: o tornar-se humano.

[...] Nesse período pude pensar na finalidade real da educação, até parece óbvio, mas no dia-a-dia da escola às vezes esquecemos da sua real importância. Ela, a educação, não está relacionada a realizar tarefas e executar atividades, ela serve para tornar o bumano, bumano e melhor, com qualidades melhores, e esse humano se refere aos alunos como também a nós, os educadores. Para isso é fundamental pensarmos o que fazemos, porque fazemos, para que, para quem e como fazemos. Assim podemos refletir o quanto precisamos mais e buscar meios para isso. Mariana.

Atribuir sentido ao trabalho também corresponde olhar para si mesmo, como processo de exotopia, como princípio que explica o acabamento do sujeito quando este é constituído pelas relações de alteridade, com base nas relações entre ele e o outro e da distância produzida pelo excedente de visão (GERALDI, 2010).

Essa dimensão de alteridade constitutiva do processo formativo pode ser observada nos enunciados a seguir, contribuindo para a atribuição de sentido para o trabalho:

[...] Sentirei saudades desses momentos riquíssimos de partilha, pois pude ampliar as minhas reflexões sobre o meu trabalho no cotidiano da escola. Em muitas falas pude me enxergar como professor coordenador em seu trabalho diário, afogado muitas vezes pelas demandas do contexto escolar e ao mesmo tempo cheia de "gás" pela busca de um trabalho de qualidade. Estar presente na formação me fez refletir sobre minha própria ação, confrontar a mim mesmo sobre o papel do professor 
coordenador enquanto articulador do projeto de formação compartilhado com os professores. Confesso que isso tem sido um desafio para mim, pois até então acreditava que os espaços de formação deveriam estar centralizados no professor coordenador. Telma.

[...] Refleti nesses encontros e continuei a refletir após os mesmos sobre a constituição dessa função em nós e percebo que neste início tudo são encontros: com as teorias, com os colegas, práticas, culturas, histórias, memórias... que esses elementos nos formam e nos de-formam (abrem para o novo e para nós o outro). Helena.

O encontro com os pares foi valorizado como oportunidade para superar o sentimento de solidão, ainda presente em alguns contextos educacionais. Fontana (2003) afirma que o silenciamento, o isolamento e a solidão não impedem apenas o fazer junto na escola, mas minam a construção de confiança no outro, como parceiro e em nós mesmos, como profissionais, "[...] uma vez que a confiança no próprio trabalho está geneticamente ligada ao aprender a analisar junto com o outro o trabalho produzido, para poder refletir sobre ele autonomamente e definir-lhe rumos e nuances" (FONTANA, 2003, p. 119).

A formação vista como espaço coletivo para parar, pensar, refletir, trocar, aprender e investigar a própria prática profissional provocou nos sujeitos o sentimento de pertencimento. Os enunciados das professoras coordenadoras também registraram o desejo e a potência dos encontros e das partilhas, bem como a necessidade de compartilharem angústias e anseios e receberem aconchego, conforto, acolhida, percebendo que não estão sozinhas, sabendo que fazem parte de um grupo:

[...] Foi bom poder estar aqui, compar-trilhar ao lado de outras colegas dos mesmos anseios ou principalmente, de pessoas mais experientes, que puderam trazer um pouquinho de si para nos afetar, isso me fez perceber que não estou sozinha nesta caminhada e que como eu já imaginava desde o início, está valendo a pena e vai valer muito a pena. Isaura.

[...] $\mathrm{Na}$ escola somos ponte, mas muitas vezes nos encontramos numa ilha deserta e só momentos como estes, vivenciados nesta formação, nos trazem o aconchego e o conforto de percebermos que, na verdade, os momentos solitários do professor coordenador existem sim, mas não estamos sożinhos, afinal. E, muitas vezes, é preciso sair da ilha para enxergar a ilha como ela realmente é. Noemi

[...] É muito gratificante e acolhedor saber que partilhamos dos mesmos medos e angústias, às vezes nos frustramos por justamente não conseguir compartilhar. Portanto, além das aprendizagens, levo também a certeza de que este caminho já está traçado, terá sempre que ser delineado com formações e contribuições generosas com as que recebemos até o momento. Lorena.

A intimidade das cartas revela que as professoras coordenadoras, em muitos momentos, se sentem sozinhas nas escolas e a formação na SME foi responsável por oferecer um grupo de pertencimento, oferecer escuta e disponibilizar tempo para que a reflexão crítica sobre o trabalho pudesse ser teorizada e transformada em projetos de ação. 
DOI: $10.12957 /$ teias. $\%$ Y.50940

\section{CONSIDERAÇÕES FINAIS}

A leitura das cartas elaboradas pelas professoras coordenadoras no encerramento do curso de formação na SME de Rio Claro/SP evidenciou sentidos da/para a formação a serem considerados na continuidade das ações da rede.

Para ocuparem a função de formadoras de professores e articuladoras do trabalho pedagógico nas escolas, as professoras coordenadoras precisam encontrar tempos e espaços de encontro na SME que lhes permitam não só ampliar seu repertório de conhecimentos e trocas de experiências, mas oportunidades para "parar" e "refletir" sobre o trabalho e em diálogo com os pares, compartilhar sentimentos que ajudem a lidar com a complexidade e as exigências do cotidiano escolar.

A formação foi compreendida como um momento de interrupção da rotina e possibilidade de deslocamento do olhar e, consequentemente, atribuição de sentido para o trabalho.

Estar entre os colegas compartilhando ideias e sentimentos reforçou o sentimento de pertencimento no grupo e valorização da função.

Como formadoras/pesquisadoras, reafirmamos nossa convicção de que a formação dos formadores no contexto da SME não pode ser planejada de modo verticalizado e ser indiferente às experiências dos sujeitos. A formação deve respeitar as necessidades e expectativas do grupo a que se dirige.

As pistas e marcas deixadas por esse grupo de professoras coordenadoras podem se constituir como referências formativas tanto para o CAP de Rio Claro, como para as demais redes de ensino.

\section{REFERÊNCIAS}

ALARCÃO, Isabel (org.). Escola reflexiva e supervisão. Uma escola em desenvolvimento e aprendizagem. Porto: Porto Editora, 2001.

BAKHTIN, Mikhail. Marxismo e filosofia da linguagem: problemas fundamentais de método sociológico da linguagem. São Paulo: Hucitec, 2011.

CANÁRIO, Rui. A prática profissional na formação de professores. Lisboa: Instituto de Inovação Educacional, 2001.

CLEMENTI, Nilba. A voz dos outros e a nossa voz: alguns fatores que intervêm na atuação do coordenador. In: PLACCO, Vera Maria Nigro Souza; ALMEIDA, Laurinda Ramalho (orgs.). O coordenador pedagógico e o espaço de mudança. São Paulo: Loyola, 2001. p. 53-66.

COLLARES, Cecília Azevedo Lima; MOYSÉS, Maria Aparecida Affonso; GERALDI, João Wanderley. Educação continuada: a política da descontinuidade. Educação e Sociedade, Campinas, v. 20, n. 68, p. 202-219, dez. 1999.

CUNHA, Renata Cristina Oliveira Barrichelo Cunha. Formação continuada de professores coordenadores: entre preocupações e proposições. Educação Unisinos, São Leopoldo, v. 18, n. 3, p. 280-287, set./dez. 2014.

CUNHA, Renata Cristina Oliveira Barrichelo Cunha; OMETTO, Cláudia Beatriz de Castro Nascimento.; PRADO, Guilherme do Val Toledo. Trabalho docente coletivo e coordenação pedagógica: entre a heterogeneidade do cotidiano e um projeto de formação de professores. Revista Educação PUC-Campinas, Campinas, v. 18, n. 2, p. 171-179, maio/ago. 2013. 
DOI: $10.12957 /$ teias. $\%$ Y.50940

FONTANA, Roseli Aparecida Cação. Como nos tornamos professoras? Belo Horizonte: Autêntica, 2003.

FREIRE, Paulo. Pedagogia da autonomia: saberes necessários à prática educativa. São Paulo: Paz e Terra, 2011.

GATTI, Bernadete Angelina. Formação continuada de professores: a questão psicossocial. Cadernos de Pesquisa, São Paulo, n. 119, p. 191-204, jul. 2003.

GERALDI, João Wanderley. Ancoragens: Estudos Bakhtinianos. São Carlos: Pedro \& João Editores, 2010.

GINZBURG, Carlo. Sinais. Mitos, emblemas, sinais: morfologia e história. São Paulo: Companhia das Letras, 1989.

JOBIM e SOUZA, Solange. Dialogismo e alteridade na utilização da imagem técnica em pesquisa acadêmica: questões éticas e metodológicas. In: FREITAS, Maria Teresa de Assunção; JOBIM e SOUZA, Solange.; KRAMER, Sonia (orgs.). Ciências bumanas e pesquisa: leituras de Mikhail Bakhtin. São Paulo: Cortez, 2003. p. 77-94.

KOHAN, Walter. A devolver (o tempo d)a infância à escola. In: ABRAMOWICZ, Anete; TEBET, Gabriela Guarnieri (orgs.). Infância e pós-estruturalismo. São Paulo: Porto de Ideias, 2017. p. 11-14.

KOLB-BERNARDES, Rosvita. Segredos do coração: a escola como espaço para o olhar sensível. Caderno Cedes, Campinas, v. 30, n. 80, p.72-83, jan./abr. 2010.

LARROSA, Jorge. Notas sobre a experiência e o saber de experiência. Revista Brasileira de Educação, Rio de Janeiro, n. 19, p. 20-18, jan./abr. 2002.

LARROSA, Jorge. Pedagogia Profana: danças, piruetas e mascaradas. Belo Horizonte: Autêntica, 2006.

MIZIARA, Leni Aparecida Souto; RIBEIRO, Ricardo; BEZERRA, Giovani Ferreira. O que revelam as pesquisas sobre a atuação do coordenador pedagógico. Revista Brasileira de Estudos Pedagógicos, Brasília, v. 95, n. 241, p. 609-635, set./dez. 2014.

NÓVOA, Antonio. Professores: imagens do futuro presente. Lisboa: Educa, 2009.

PLACCO, Vera Maria Nigro Souza; ALMEIDA, Laurinda Ramalho; SOUZA, Vera Lúcia Trevizan. O coordenador pedagógico $(\mathrm{CP})$ e a formação de professores: intenções, tensões e contradições. Estudos e Pesquisas Educacionais, São Paulo, n. 2, p. 227-288. 2011.

PLACCO, Vera Maria Nigro Souza; SOUZA, Vera Lúcia Trevizan; ALMEIDA, Laurinda Ramalho. O coordenador pedagógico: aportes à proposição de políticas públicas. Cadernos de Pesquisa, São Paulo, v. 42, n. 147, p. 754-771, set./dez. 2012.

PINTO, Keila Santos. Desdobramentos das escritas de educadoras nos espaços de formação na escola. 193p. Dissertação (Mestrado em Educação), Programa de Pós-Graduação em Educação, Instituto de Biociências, Universidade Estadual Paulista, Rio Claro, 2016.

SOLIGO, Rosaura. Venho por meio desta...In: PRADO, Guilherme do Val Toledo; SOLIGO. Rosaura. (orgs.). Porque escrever é faz̧er história: revelações, subversões, superações. Campinas: Alínea, 2007. p. 323-362

RIO CLARO. Secretaria Municipal da Educação. Estatuto do Magistério dos Profissionais da Educação do Município de Rio Claro - Lei Complementar no 024/2007. Dispõe sobre o Estatuto do Magistério Público Municipal do Município de Rio Claro. Disponível em 
DOI: $10.12957 /$ teias. $\%$ Y.50940

http://www.educacaorc.com.br/media/biblioteca/21/consolidacaodaleicomplementar2.pdf. Acesso em 7 maio 2020.

RIO CLARO. Secretaria Municipal da Educação. Decreto n 8604/2009, de 27 de janeiro de 2009. Dispõe sobre a organização e funcionamento das Horas de Trabalho Pedagógico - HTP Coletivo, Individual e Livre dos docentes, estatutários e contratados da Rede Municipal de Ensino de Rio Claro para o ano letivo de 2013. Disponível em http://www.educacaorc.com.br/media/biblioteca/7000454/res005 htpc.pdf. Acesso em 7 maio 2020.

RIO CLARO. Secretaria Municipal da Educação. Decreto n 11.578, de 09 de setembro de 2019. Regulamenta os procedimentos de designação para função da classe de Suporte Pedagógico de Professor Coordenador, de Profissionais do Magistério estáveis do Quadro 1 e Quadro 2, para exercício nas Unidades Educacionais, da Secretaria Municipal da Educação, nos termos do inciso II do artigo 51 da Lei Complementar 024/2007 e suas alterações e dá outras providências. Disponível em: http://www.educacaorc.com.br/media/biblioteca/7005174/DECRETO\%2011578-2019\%20\%20Prof $\% 20$ Coordenador.pdf. Acesso em: 7 de maio de 2020.

RIO CLARO. Secretaria Municipal da Educação. Resolução SME 003/2019, de 21 de janeiro de 2019. Dispõe sobre a organização e funcionamento das Horas de Trabalho Pedagógico - HTP Coletivo, Individual e Livre dos docentes, estatutários e contratados da Rede Municipal de Ensino de Rio Claro para o ano letivo de 2019. Disponível em http://www.educacaorc.com.br/media/biblioteca/7004651/Resolu $\% \mathrm{C} 3 \% \mathrm{~A} 7 \% \mathrm{C} 3 \% \mathrm{~A} 3 \mathrm{o} \% 20 \mathrm{SM}$ E\%20003-2019\%20-\%20HTP.pdf. Acesso em 7 maio 2020.

\section{Informações das autoras}

Renata Cristina Oliveira Barrichelo Cunha

Centro Universitário Salesiano de São Paulo

E-mail: renata_bcunha@yahoo.com.br

ORCID: https://orcid.org/0000-0002-5662-8062

Link Lattes: http://lattes.cnpq.br/4014320163579450

Keila Santos Pinto

Secretaria Municipal de Educação de Rio Claro

E-mail: keila_sp22@yaho.com.br

ORCID: https://orcid.org/0000-0003-2543-4078

Link Lattes: http://lattes.cnpq.br/0983570787545451 